\title{
124 ERROS DE REVISÃO!
}

\section{Marcos Antonio de Moraes}

Universidade de São Paulo

\section{Resumo}

Buscando historiar os percalços da segunda edição dos contos de Belazarte [1944] de Mário de Andrade, pela AmericEdit (RJ) de Max Fischer, este artigo pretende refletir sobre a importância do "corpo da obra literária" e da "história deste corpo" - no dizer de Antonio Candido em Noções de análise histórico-literária (1959/2005) -, para o pleno exercício do trabalho de análise e interpretação literária. Tenciona ainda fornecer elementos biobibliográficos de fonte primária inéditos (cartas, manuscritos, documentação de periódicos, dedicatória) tanto para o aprofundamento de indagações da crítica textual, quanto para a definição de novos ângulos de apreensão do funcionamento do sistema literário brasileiro, em meados do século XX.

\section{Abstract}

Seeking to historify the hindrances of the second edition of Mário de Andrade's short stories of Belazarte [1944] for the Americ-Edit (Rio de Janeiro) of Max Fischer, this article intends to reflect on the importance of the "body of the literary composition" and the "history of this body" - as put by Antonio Candido in Noções de análise histórico-literária (1959/2005) -, for the full exercise of the work of analysis and literary interpretation. It still intends in such a way to supply unknown bio-bibliographical elements of primary source (letters, manuscripts, documentation of periodicals, dedication) to the deepening of investigations of textual criticism, as well as to the definition of new angles of apprehension of the functioning of the Brazilian literary system, in mid 20th century. [trad. Ivan Fonseca]

\author{
Palavras-chave \\ Mário de \\ Andrade; \\ Belazarte; \\ sistema literário \\ brasileiro; \\ correspondência; \\ crítica textual
}

\section{Keywords}
Mário de
Andrade;
Belazarte:
Brazilian
literary system; correspondence; textual criticism 
"[...] o estudioso [da literatura] precisa valer-se de um texto impresso fidedigno, que possa consultar com segurança, por saber que está escoimado de erros e corresponde o mais possível ao original do A." (Antonio Candido, Noções de análise histórico-literária, pp. 47-8).

\section{Belazarte nas mãos de Max Fischer}

ocumentando os passos do acordo para a reedição dos contos de Belazarte, Mário de Andrade conservou em seu arquivo a cópia desta carta endereçada ao diretor da Americ-Edit:

São Paulo, 26-VIII-43

\section{Caro amigo, Sr. Max Fischer}

Recebi sua carta e lhe respondo imediatamente.

Além da enfermidade, de que aliás vou bem melhor, encomendas urgentes de estudos e de dois livros é que me impediram terminar mais cedo a revisão do meu livro de contos Belazarte. Mas devo terminá-la na semana próxima, o mais tardar, e então a enviarei para a Americ-Edit.

Desejo receber porém alguns esclarecimentos seus, quanto ao[s] meus direitos autorais:

I - Se são os mesmos, iguais aos que já recebi pela edição dos Aspectos da literatura brasileira;

II - Se, como da primeira vez, deverei abrir mão de parte deles para propaganda do livro.

Peço-lhe desculpas, caro Amigo, por tocar em assunto tão desagradável, mas isso deriva de costume velho meu, com que tenho me dado sempre bem. Ao contrário do comum dos escritores, jamais me queixei dos meus editores e sempre fiquei amigo de todos eles. E atribuo esta felicidade a ter sempre esclarecido preliminarmente as condições materiais da edição dos meus livros.

Acredite, caro Amigo, que é com prazer que o vejo de novo manifestando a sua atuação literária em nosso meio. Estava com receio que o Canadá o roubasse para sempre do Brasil.

Com a admiração sempre muito grata e amiga de

Mário de Andrade ${ }^{1}$.

${ }^{1}$ Carta assinada à máquina: "Mario de Andrade"; datiloscrito, cópia carbono azul; papel creme, filigrana; 1 folha; 25,8 x 20,7 cm (Arquivo Mário de Andrade, Série Correspondência, Instituto de Estudos Brasileiros, Universidade de São Paulo). As cartas transcritas neste artigo foram atualizadas de acordo com a norma ortográfica vigente; foram conservadas as idiossincrasias linguísticas de Mário de Andrade). 
Modelo de urbanidade, a carta do criador de Macunaíma busca, objetivamente, esclarecimentos sobre cláusulas contratuais de edição. De modo alusivo, o texto traz à tona aspectos da intimidade do remetente (doença), informa projetos em andamento (estudos e livros) e o trabalho de reescritura das narrativas de Belazarte, obra cuja primeira edição, de 1.000 exemplares, em 1933, paga pelo autor, recebeu o selo da Editora Piratininga de São Paulo. A missiva, pouco extensa, mas fecunda em assuntos biobibliográficos, acolhe ainda o testemunho das relações do autor modernista com o mercado de livros no Brasil, mostrando, em particular, os seus vínculos com o editor e contista judeu francês, Max Fischer (1880-1957), ex-diretor da prestigiosa Flammarion, refugiado no Brasil na Segunda Guerra Mundial. A mensagem cordata, entretanto, não deixa entrever o desfecho desastroso da empreitada em negociação.

Logo no início de 1945, Mário teve sob os olhos um exemplar da acalentada segunda edição de Belazarte, brochura in-octavo, 19,7 x 13,3cm, com 201 páginas. A capa bege, sem ilustração figurativa, espelhava-se na sobriedade dos livros produzidos na França; trazia somente, em preto, o nome do autor, o título da obra e a indicação da casa editora, centralizados em retângulo alaranjado. Na página de rosto, indicava-se a existência de "cinco exemplares, fora de comércio,/em papel de Linho "Imperial Ledger'”. A nova edição abrigava "O besouro e a Rosa", "Jaburu malandro", "Caim, Caim e o resto", "Menina de olho no fundo", "Túmulo, túmulo, túmulo", "Piá não sofre? Sofre." e "Nízia Figueira, sua criada.". Do conjunto de narrativas estampadas na primeira edição de Belazarte, Mário de Andrade havia retirado. "O caso em que entra bugre", depois radicado nas páginas da Obra imatura, que passou a integrar a segunda edição de Primeiro andar. Desse mesmo livro, saído do prelo em 1926, o autor foi buscar para Belazarte "O besouro e a Rosa". A simpática materialidade da obra parecia atender à vontade do escritor de conjugar, em correto diapasão, textos de um consistente projeto estético-literário modernista. Por fora, bela viola; dentro, pão bolorento. Cortada as bordas das páginas, a leitura de Mário, divisando tantas infidelidades textuais, encontrou pela frente um caminho de pedras.

Três cartas de Mário de Andrade, no período, recuperam o seu angustioso estado de ânimo e as primeiras providências tomadas no caso. Em 7 de fevereiro, dirige-se ao jovem jornalista carioca, Guilherme de Figueiredo, que ocupava a função de tesoureiro da ABDE, a Associação Brasileira de Escritores, então presidida pelo escritor Aníbal Machado. Mário e Guilherme, afinados por interesses musicais e literários, tinham construído firmes laços de amizade entre 1938 e 1941, tempo em que o escritor paulistano vivera no Rio de Janeiro. Mário podia, assim, desabafar:

[...] preciso me expandir com você. Sobretudo com o caso do Belazarte [...]. Você já deve estar inteirado do caso pelo Aníbal, pois entreguei à ABDE daí a solução do caso. A razão de entre- 


\begin{abstract}
gar à ADBE são duas razões: A $1^{a}$. é que era a entidade qualificada pra isso e eu não quis fazer imediatamente por mim um litígio jurídico. A $2^{\text {a }}$. é o meu problema particularíssimo de eu estar publicando as minhas Obras Completas, e poder parecer por isso, que estou com má-vontade, criando caso, só pra tirar o Belazarte, do Fischer, e o dar logo pro Martins. Sou incapaz disso, embora, está claro, todo o meu desejo, seja de passar o Belazarte o mais depressa possível pras Obras Completas.// Mas desejo não implica ação, sobretudo ação desairosa pra mim. Aliás, resisti a muitos convites e insinuações de safadezas, feitas por amigos, nesse sentido. E ainda mais, quando recebi proposta do Martins para as Completas, embora ainda não tivesse contrato assinado, e sequer estipulado com o Fischer, só porque tinha infelizmente prometido a este, por promessa bocória, lhe ceder o Belazarte, resisti a todos os convites do Martins e de outros pra não faltar à minha promessa. Nem sequer conseguiu de mim pedir ao Fischer que me desligasse da promessa, porque, sendo um caso comercial, mesmo isso me pareceu repulsivo. E foi, confesso, com a morte n'alma que assinei o contrato e cumpri a promessa. E agora me sucede isso! Não deixa de ler a carta que mandei pro Aníbal e a lista dos erros (já achei mais um por acaso, sem procurar...), peça a ele, autorizo você, se acaso por discrição ainda não leu. Aliás acabo de telegrafar mais uma vez ao Anibal protestando, porque a Americ-Edit continua distribuindo o livro, que já chegou aqui. É possível que o envio ao correio ou estrada-de-ferro, não sei, seja anterior ao estouro do caso, mas a Americ devia escrever imediato ou mesmo telegrafar aos distribuidores impedindo que pusessem o livro à venda antes de solucionado o caso. Enfim, quando houver qualquer solução peço a você me telegrafar pra meu repouso. Ando obcecado, inquieto, indignado, com tudo isso vem [sic] me ferir justo num livro que eu quero tanto bem e na sua primeira apresentação legítima. Acho tão bonito esse meu livro...2
\end{abstract}

Em 15 de fevereiro, Mário, dirigindo-se a Newton Freitas, escritor de tendência comunista expatriado na Argentina, retoma o caso, para revelar o estrago que sua obra sofrera: "Estou brigando com a Americ-Edit que fez uma edição do Belazarte que em 180 e poucas páginas tinha 124 erros de revisão!". ${ }^{3}$ Tempo de inquietude, quando ainda confessa, em outra carta a Guilherme Figueiredo, no dia 16, o propósito de aguardar o andamento do processo, sem "fazer bulha", imaginando que "muita gente [...] iria gozar com o caso, [e] até amigos". Pretendia ficar na expectativa do julgamento da ABDE, mas se perdesse o pleito envolvendo o "tortuoso" Max Fischer, estaria pronto a "desautorizar publicamente o livro". ${ }^{4}$ Morrendo pouco mais de uma semana depois, no dia 25, o escritor não testemunhou o desenlace da contenda.

De qualquer forma, estavam colocadas na ordem do dia as tensas relações entre autores e editores no sistema literário brasileiro, do mesmo modo que se trazia à baila o pouco cuidado com o texto no processo de publicação. O desvirtuamento da matéria textual atingia em cheio o escritor em sua atividade de criação, a crítica profissional e, principalmente, o leitor, tornados todos reféns de interesses, muitas vezes, exclusivamente comerciais. Acompanhar, desde o princípio, a narrativa da desventura do Belazarte corrompido pelo procedimento editorial a ela incorporando as reflexões de Mário de Andrade sobre o assunto,

${ }^{2}$ Andrade, Mário de. A lição do guru: Cartas a Guilherme Figueiredo. 1937/1945. Ed. prep. pelo destinatário. Rio de Janeiro, Civilização Brasileira; 1989. p. 154.

${ }^{3}$ Andrade, Mário de. Carta a Newton Freitas, 15 fev. 1945. Revista do Instituto de Estudos Brasileiros, n. 17, São Paulo, p. 120.

${ }^{4}$ Andrade, Mário de. A lição do guru, op. cit, p. 158. 
valida, agora, a importância de se considerar a literatura também em sua materialidade (texto fidedigno, tendo em vista as intenções do autor), história (condições da produção do livro) e recepção (memória da leitura).

"o mínimo possível de erros de impressão. Se possível nenhum."

A carta de Mário ao editor da Americ-Edit, Max Fischer, em 26 de agosto de 1943, pedindo esclarecimentos sobre as cláusulas de edição de Belazarte encadeia-se em uma pequena correspondência conservada pelo escritor em seu arquivo, atualmente no patrimônio do Instituto de Estudos Brasileiros da Universidade de São Paulo. ${ }^{5}$ Esse diálogo epistolar, circunscrito entre 1942 a 1943, subsiste em cartas (originais e cópias), telegramas e cartões de visita. Congrega 35 mensagens da Americ-Edit, assinadas por seu diretor ou por seus funcionários, algumas delas em francês. Em contrapartida, entre aquelas subscritas pelo autor de Paulicéia desvairada, ou por seu secretário, José Bento Faria Ferraz, restam 13 cópias datiloscritas, que tiveram a finalidade de registrar remessas de textos, definir ajustes contratuais, indicar a destinação de exemplares comuns e especiais, aceitar ou declinar propostas de publicação.

Entre as recusas de Mário, conta-se os Prazeres da música, título inventado por Fischer para obra que, com insistência, tentou arrancar do autor de Música, doce música. Se, em novembro de 1943, opôs-se categoricamente à sugestão do editor, pois, em "tempos de guerra e de insoluções nacionais", ao se afastar "mais das preocupações estéticas", lhe seria "talvez mais fácil escrever sobre as 'Dores da Música', que sobre os seus prazeres", ${ }^{6}$ pode-se, de certa maneira, considerar que Mário firmou boa parceria com a Americ-Edit. Confia a Fischer, em 1942, o capítulo "Arte inglesa", para Inglaterra, livro planejado por Fischer; em 1943, a primeira edição dos Aspectos da literatura brasileira e no mesmo ano, Belazarte reformulado. Da editora carioca, em março de 1943, um mês antes de se transferir do Edifício Metropolitano, na Rua Álvaro Alvim, 31, para a Rua do Rezende, 80, porque as instalações tinham ficado "demasiado pequenas para as nossas necessidades", ${ }^{7}$ vem, também, o convite para "publicar todas as [...] novas obras" de Mário e "aos poucos, reeditar os livros antigos" que, segundo a opinião do escritor, "não devem permanecer esgotados". ${ }^{8}$ Em outubro desse

${ }^{5}$ Os projetos Organização da Série Correspondência de Mário de Andrade, Catálogo da Série Correspondência de Mário de Andrade, Preparo para publicação do Catálogo da Série Correspondência de Mário de Andrade e Preparo do CD-ROM da Série Correspondência de Mário de Andrade, foram coordenados pela Profa. Dra ${ }^{a}$. Telê Ancona Lopez, com Auxílio Pesquisa BID, Vitae e Fapesp, entre 1989-1997; e 2000-2003.

${ }^{6}$ Carta de Mário de Andrade a Americ-Edit/Max Fischer, 20 nov. 1943 (Arquivo Mário de Andrade, Série Correspondência, IEB-USP).

${ }^{7}$ Carta de Mário de Andrade a Americ-Edit/Max Fischer, 12 abr. 1943 (Arquivo Mário de Andrade, Série Correspondência, IEB-USP).

${ }^{8}$ Carta de Mário de Andrade a Americ-Edit/Max Fischer, 19 mar. 1943 (Arquivo Mário de Andrade, Série Correspondência, IEB-USP). 
ano, ao vislumbrar a possibilidade de editar em inglês a obra de ficção de Mário nos Estados Unidos, Max Fischer volta à carga: "Eu lhe havia dito sobre o meu grande desejo de me tornar uma espécie de editor exclusivo de Mário de Andrade durante um tempo determinado: dez anos por exemplo". Enumera, então, as " grandes vantagens" do consórcio: "facilita, para o livreiro, o reabastecimento [...] permite ao editor aumentar os seus esforços, porque ele sabe com antecedência que se tal ou tal livro tiver uma saída um pouco menos brilhante, ele terá ocasião em seguida de se ver, apesar de tudo, recompensado por sua fiel admiração e seus esforços./Ele permite ao autor de trabalhar tranqüilamente, sabendo que tem no seu editor um colaborador dedicado e sempre à sua disposição". "A consideração de Max Fischer por Mário Andrade, parecia, contudo, ultrapassar os interesses comerciais imediatos. Pelo menos é o que se depreende da dedicatória que deixa no volume - hors commerce - reunindo contos de sua autoria, textos inicialmente publicados na França e agora, também, pela Americ-Edit: "Tenha a bondade,/caro Mário de Andrade,/de aceitar este exemplar/de/PRÉSENCE DU PASSÉ [impresso]/como homenagem de minha grande/admiração por seu incomparável/talento, tão humano e duma inteligência/tão aguda,/Max F./Rio/42". ${ }^{10}$

Segundo Ubiratan Machado, em "A literatura francesa no Brasil durante a II Guerra Mundial", a Americ-Edit, fundada "no final de 1940 ou início de 1941", resistiu até 1946. Em princípio, tinha em mira a publicação de obras em francês, abarcando, principalmente, a prosa, a poesia, o teatro, a história e o memorialismo dos século XIX e XX. Resguardava-se de "aventuras editoriais", ao eleger autores conhecidos do público brasileiro. Causou espécie, contudo, ao publicar, no tempo do Estado Novo, a biografia de Getúlio Vargas, de Paul Frischauer, em tradução francesa de Pierre Morel, trazendo o subtítulo Un portrait sans retouches; divulga ainda, do presidente, o seu Discurso de posse na Academia Brasileira de Letras, proferido em dezembro de 1943. O catálogo, a partir de 1944, passou a estampar traduções e obras em português, com destaque para a "Coleção Joaquim Nabuco", dirigida pelo crítico Álvaro Lins e inaugurada com os Aspectos da literatura brasileira de Mário de Andrade. Nessa coleção, Manuel Bandeira deu as suas Poesias completas e Carlos Drummond de Andrade, as Confissões de Minas. Em relativamente pouco tempo, a editora de Fischer deixou um legado bastante expressivo, oferecendo às livrarias "120 títulos, em 128 volumes (salvo seja), uma média de 24 títulos anuais". ${ }^{11}$ Atividade intensa, confirmada na carta de Murilo Miranda a Mário, em fevereiro de 1942: "o serviço aqui é puxado, temos mais de quarenta livros em fabricação, livros que se recusam a ver a luz do

\footnotetext{
${ }^{9}$ Carta de Mário de Andrade a Americ-Edit/Max Fischer, 11 out. 1943 (Arquivo Mário de Andrade, Série Correspondência, IEB-USP).

${ }^{10}$ Acervo bibliográfico de Mário de Andrade, IEB-USP.

${ }^{11}$ Ubiratan Machado. A literatura francesa no Brasil durante a II Guerra Mundial. Revista Brasileira, fase VII, abril-maio-junho 2005, ano XI, n. 43, p. 255.
} 
dia por maior que seja o sol". ${ }^{12}$ Murilo, amigo moço de Mário, jornalista ligado ao grupo da Revista Acadêmica que congregava, no Rio de Janeiro, universitários de marcada tendência política de esquerda, cumpriu, na editora, serviços de publicidade, entre dezembro de 1941 e meados de 1943. Dentro da empresa, Murilo serviu, muitas vezes, de intermediador entre os interesses de Mário e os de seu "patrão".

O primeiro texto de Mário na Americ-Edit, "Arte inglesa", encomendado para o volume Inglaterra, foi remetido ao editor em maio de 1942. Premido pela falta de tempo, o autor, em carta, justifica-se; o ensaio, que para ser entregue necessitou de um prazo maior do que o previsto, não agradou inteiramente a Mário: "Sou obrigado a lhe confessar que o meu trabalho está longe de me satisfazer, e embora isto se deva à gageure difícil de escrever conjuntamente sobre artes muito diferentes entre si, minha vaidade me segreda que com maior liberdade de tempo e espaço, eu poderia produzir coisa melhor. Sou muito lento no escrever, e se acaso o capítulo não entrar já na tipografia, lhe peço me avisar de quanto tempo ainda poderei dispor para lhe enviar outra cópia mais limpa e um pouco mais trabalhada". ${ }^{13}$ Em 10 de julho de 1942, recorre a Murilo Miranda para providenciar pequenas correções no estudo, enviando-lhe uma listagem. ${ }^{14}$ Em novembro desse ano, sem notícias do texto, Mário deseja desistir da publicação e "reassumir a propriedade do ensaio, caso ele esteja livre", 15 ao sondar o amigo, recebe, em tom brincalhão, o aviso: "nós vamos editar o bicho. O capítulo, portanto, continua sendo nosso, muito nosso, todo nosso". ${ }^{16}$ No ano seguinte, em novembro, ainda sem conhecer o destino de sua "Arte inglesa", Mário, cautelosamente, toca no assunto em carta a Max Fischer: "relendo outro dia o capítulo que lhe mandei sobre 'Arte inglesa' fiquei horrorizado comigo mesmo. Não nego que duas ou três noções críticas fundamentais desse estudo, eu as conservo e defendo, mas o estudo está horrível, dum brilho malabarístico e duma falsa virtuosidade facílima. Como pude escrever para um livro, semelhante 'valsa vienense'! Vou ver se aproveito alguma parte dessas virtuosidades lisztianas em jornal. Para o seu livro escreverei novo estudo, espero que mais sério e honesto". ${ }^{17}$ Recebe a resposta do editor, datada de 25 de novembro de 1943: "me vejo obrigado a lhe confessar que não estou de acordo consigo quan-

${ }^{12}$ Carta de Murilo Miranda a Mário de Andrade, 4 fev. 1942 (Arquivo Mário de Andrade, Série Correspondência, IEB-USP).

${ }^{13}$ Carta de Mário de Andrade a Americ-Edit/Max Fischer, 30 maio 1942 (Arquivo Mário de Andrade, Série Correspondência, IEB-USP).

${ }^{14}$ A cópia desse documento foi conservada por Mário de Andrade. No folha, registra: "Correções que já pedi ao Murilo fazer a 10-VII-42". (Arquivo Mário de Andrade, Série Manuscritos Mário de Andrade - $O$ baile das quatro artes, IEB-USP).

${ }^{15}$ Carta de Mário de Andrade a Murilo Miranda, 5 nov. 1942 (Arquivo Mário de Andrade, Série Correspondência, IEB-USP).

${ }^{16}$ Carta de Murilo Miranda a Mário de Andrade, 20 nov. 1942 (Arquivo Mário de Andrade, Série Correspondência, IEB-USP).

${ }^{17}$ Carta de Mário de Andrade a Max Americ-Edit/Fischer, 20 nov. 1943 (Arquivo Mário de Andrade, Série Correspondência, IEB-USP). 
do desfaz no belo capítulo que escreveu para Inglaterra. Visto que não sou teimoso eu encararia com prazer a substituição que me pede fazer. Infelizmente é muito tarde para isto. Depois de todos os contratempos e atrasos que surgiram, Inglaterra aparece agora - enfim - como fora da categoria de projeto de livro, para se tornar um livro, e o serviço de fabricação já o confiou a um impressor./ Naturalmente se Você deseja separar 1/4 ou o 1/3 deste estudo para uma prépublicação num jornal, não posso senão concordar com este desejo. Será naturalmente isto uma pena para o livro [...]". ${ }^{18}$ "Arte inglesa", no final desse ano, chegaria aos leitores da Folha da Manhã de São Paulo, em uma série de cinco artigos. ${ }^{19}$ Postumamente, seria incluído nas Obras Completas de Mário de Andrade, na segunda edição do O baile das quatro artes (1963), conforme o desejo do escritor. ${ }^{20}$

Os Aspectos da literatura brasileira, em seu processo de edição, sofreram poucas atribulações na Americ-Edit. A publicação da obra vinculou-se ao convite de Álvaro Lins, diretor da coleção, que se propunha congregar títulos de autores representativos da cultura brasileira. O projeto contemplava o "ecletismo de nomes, de assuntos, de gêneros", em livros nos quais o leitor pudesse ter "confiança quanto à autoridade dos autores e honestidade dos seus propósitos; em relação, sobretudo, com o seu intrínseco valor cultural e seguro bom gosto artístico". ${ }^{21} \mathrm{Na}$ apresentação da "Coleção Joaquim Nabuco", estampada no primeiro volume, o coordenador justifica a escolha de Mário de Andrade, "mestre de gerações mais novas", para abrir a coleção: "Não somos amigos pessoais, não somos da mesma região, não apresentamos uma coincidência de idéias. Esta escolha explica, então, o que haverá de ausência de parti pris nos demais livros e autores. Escolhemos o Sr. Mário de Andrade pela autoridade do seu nome ilustre através de uma obra de poeta, ficcionista, ensaísta, historiador, folclorista. Aqui se encontrará o ensaísta na interpretação e no estudo de figuras brasileiras de tempos diversos em face das idéias e do gosto dos dias de hoje". ${ }^{22} \mathrm{Na}$ realidade, Álvaro Lins pôde escolher os Aspectos entre outros títu-

${ }^{18}$ Carta de Americ-Edit/Max Fischer a Mário de Andrade, 25 nov. 1943 (Arquivo Mário de Andrade, Série Correspondência, IEB-USP).

19 Mário de Andrade preservou em seu arquivo três versões datiloscritas de Arte inglesa, textos intensamente rasurados por ele. A estas versões, reuniu a série de cinco artigos saídos em sua coluna "Mundo Musical" da Folha da Manhã. Recortados do jornal e colados em folhas de papel, os artigos perderam a indicação de data; dois deles, contudo, ostentam essa informação a lápis, feita certamente pelo secretário do escritor ("Arte inglesa", "Arte inglesa II", "Arte inglesa III [9-12-43], "Arte inglesa IV [16-12-43], "Arte inglesa (fim)"). (Arquivo Mário de Andrade, Série Manuscritos Mário de Andrade - O baile das quatro artes, IEB-USP).

${ }^{20}$ A primeira edição de O baile das quatro Artes [1942] veio a lume pela Livraria Martins Editora de São Paulo, como o segundo livro da Coleção Mosaico. No arquivo de Mário, ao lado dos datiloscritos e recortes jornalísticos relacionados a "Arte inglesa", o escritor acrescentou o bilhete: "Baile das 4 artes/ Falta 'Arte inglesa'." (Arquivo Mário de Andrade, Série Manuscritos Mário de Andrade - O baile das quatro artes, IEB-USP).

${ }^{21}$ Álvaro Lins. Coleção Joaquim Nabuco. Em Mário de Andrade. Aspectos da literatura brasileira. Rio de Janeiro: Americ-Edit; 1943. p. 7-8.

${ }^{22}$ Ibidem, p. 10. 
los que Mário lhe enviara, pelas mãos de Manuel Bandeira, com quem o autor, inicialmente, se aconselhou. "Vão três!", escreve ao amigo poeta, "um de crônicas literárias, o de ensaios críticos e do artigo de artigos de crítica literária". O primeiro deles, Os filhos da Candinha, o terceiro, textos "de uma contemporaneidade bem maior que a dos ensaios", ${ }^{23}$ foi posteriormente nomeado $0 \mathrm{em}$ palhador de passarinho.

Volume "muito grande" na opinião de Max Fischer, ${ }^{24}$ os Aspectos perdem o ensaio "Manuel Bandeira", embora a "Advertência" da edição princeps faça referência à presença dele no volume. A opinião do editor, em todo caso, viera a calhar, pois ao autor desgostava a linguagem do estudo de 1924, vincada por certo cabotinismo da expressão modernista. Somente quando a obra sai do prelo, o editor escreve a Mário, em 12 de janeiro de 1942, lembrando que "nous n'avions, en somme, rien envisagé au point de vue conditions relativement à sa publication". Sabendo que no Brasil é "usual" o pagamento de 10\% de direitos autorais, calculados a partir do preço de capa, o editor faz as contas: o volume custará ao leitor Cr\$ 14,00. Em uma tiragem de 1500 exemplares, da qual se retirará 197 direcionados à distribuição, tem-se um crédito de Cr\$1.824,20. Bom comerciante, Max Fischer pondera que, em se tratando de livro de crítica, "a priori", "la vente est un peu plus malaisée". Argumenta, assim, em favor da cessão de parte desses proventos para aumentar o "budget de la publicité". ${ }^{25}$ Mário, em sua resposta, na carta de 15 de fevereiro, transfere a decisão ao editor: "quanto ao problema de retirar da soma de Cr\$1.824,20, uma determinada importância para auxiliar a publicidade do livro, estou perfeitamente de acordo com isso. O que não posso imaginar, de forma alguma, é a quantia com que deve concorrer para isso, pois nunca me meti em problemas desta natureza. Acha o Sr. que deixando a meu crédito uma importância redonda de Cr\$1.500,00 ou mesmo Cr\$ $1.000,00$, e dispondo do resto para interesse publicitários, este restante seria suficiente como colaboração minha? Peço-lhe o favor de resolver francamente a respeito". ${ }^{26}$ Quatro dias depois, vem a resposta, na qual o editor não demonstra hesitação: "Je joins à cette lettre un chèque de Cr\$1.000,00, à votre ordre". ${ }^{27}$ Para atar pontas neste artigo: quando, na carta de novembro de 1943, Mário indaga as condições para a edição de Belazarte, tem em mente, para decidir, essa postura comercial de Max Fischer.

${ }^{23}$ Carta de Mário de Andrade a Manuel Bandeira, 20 abr. 1942. Mário de Andrade; Manuel Bandeira. Correspondência. São Paulo, Edusp/IEB, 2000, p. 660.

${ }^{24}$ Cartas de Mário de Andrade a Álvaro Lins. Ed. prep. por José César Borba e Marco Morel. Rio de Janeiro, José Olympio, 1983, p. 67.

${ }^{25}$ Carta de Americ-Edit/Max Fischer a Mário de Andrade, 12 fev. 1943 (Arquivo Mário de Andrade, Série Correspondência, IEB-USP).

${ }^{26}$ Carta de Mário de Andrade a Americ-Edit/Max Fischer, 15 fev. 1943 (Arquivo Mário de Andrade, Série Correspondência, IEB-USP).

${ }^{27}$ Carta de Americ-Edit/Max Fischer a Mário de Andrade, 19 fev. 1943 (Arquivo Mário de Andrade, Série Correspondência, IEB-USP). 
As provas da composição dos Aspectos da literatura brasileira tiveram uma primeira leitura de Mário. Ao devolver a Murilo Miranda essa versão, em 28 de novembro de 1942, deixa claro a sua expectativa em relação à tarefa a ser cumprida pela editora, tanto quanto o seu grau de exigência: "Realmente são tão poucas as páginas em que, com alguma leitura rápida, não encontrei erro de impressão, que mando tudo. As modificações eram poucas e estão feitas.//Se defato são primeiras provas já estão excelentes. Mas o que Max Fischer combinou comigo quando esteve aqui foi mandar apenas as últimas provas pra eu fazer uma leitura derradeira. Essas, sim, é que eu quero pra ver a disposição, principalmente de versos exemplificadores, e deixar escapar o mínimo possível de erros de impressão. Se possível nenhum./Estas provas que lhe faço voltar só li por alto. Deve ter escapado muito erro e por isso não se fiem nas minhas correções. E que diabo! Justo a 'Elegia de abril' está muito maltratada, é o estudo que tem mais erros. Por favor, peça à Vanny (ainda é ela?) que faça uma revisão enérgica de tudo".28

Os Aspectos foram bem acolhidos pelo público leitor; em setembro de 1943, poucos meses depois do lançamento, restavam no estoque da Americ-Edit 681 exemplares. ${ }^{29}$ Esse dado comercial alvissareiro deve ter impelido o editor a insistir com Mário de Andrade para publicar, o mais rapidamente possível, o Belazarte. A edição do livro, pelo que se depreende de carta de Fischer a Mário, em 16 de junho de 1943, na qual o interroga sobre o andamento do trabalho de "revisão" dos contos, já possuía a anuência do escritor. Restava, ainda, a definição das cláusulas contratuais. Mário, então, quer saber as condições na cordial carta de 26 de agosto. Fischer, na resposta de 9 de setembro, demonstra a conveniência, de sua parte, em ratificar o acordo vigente na edição dos Aspectos. Mário, em missiva hoje não conhecida, deve ter sugerido, entretanto, alguns ajustes. $\mathrm{O}$ editor, respondendo a essa carta, em 11 de outubro, coloca-se "naturalmente, inteiramente de acordo com o a) o b) e o c)" das proposições do escritor; nesse documento, reporta-se também a um futuro projeto do escritor, no tocante a Belazarte: "Se lhe é verdadeiramente agradável prever desde já a publicação de uma edição ilustrada de luxo, por um preço superior a Cr\$200,00, e que deverá aparecer 2 anos mais ou menos após ser posta à venda a edição Americ-Edit de Belazarte, não farei objeção à realização deste plano". ${ }^{30}$ As negociações estavam, aparentemente, bem afinadas, mas, vistas de agora, faltava pouco para a engrenagem dar mostras de emperramento. E não se pode desprezar a confidência de Mário feita a Murilo Miranda, em carta de outubro de 1942, na qual relatava a visita que lhe fizera Max Fischer em São Paulo; antipatizou com o editor "sinu-

${ }^{28}$ Carta de Mário de Andrade a Murilo Miranda, 28 nov. 1942. Mário de Andrade. Cartas a Murilo Miranda, 1934-1945. Ed. prep. por Raúl Antelo. Rio de Janeiro, Nova Fronteira, 1981, p. 134.

${ }^{29}$ Carta de Americ-Edit/Max Fischer a Mário de Andrade, 9 set. 1943. (Arquivo Mário de Andrade, Série Correspondência, IEB-USP)

${ }^{30}$ Carta de Americ-Edit/Max Fischer a Mário de Andrade, 11 out. 1943 (Arquivo Mário de Andrade, Série Correspondência, IEB-USP). 
oso, bancando importante ‘quando estive com Mussolini' ou 'quando o papa me mandou chamar"" 31

Mário de Andrade que, em sua atuação pública, desde, pelo menos, a conferência "O movimento modernista" de 1942, vinha advogando pela maior participação do artista nas causas do tempo, ao ser entrevistado, no início de janeiro de 1944, por Francisco de Assis Barbosa, para a revista Diretrizes do Rio de Janeiro, incita a todos, agora, a lutar contra o nazismo - 'Todos são responsáveis!". Afinal, assevera, é "a essência mesma duma civilização que periclita". ${ }^{32}$ Em 21 do mesmo mês, Moacir Werneck de Castro, moço ligado à Revista Acadêmica, no artigo "Resposta a um editor francês" do Diário Carioca, retoma os "reparos" que fizera na imprensa, semanas antes, às atividades editoriais de Max Fischer no Brasil. Mário conservou em seu arquivo esse texto, no qual se lê, nos dois primeiros parágrafos:

\footnotetext{
Dizíamos, em suma [no primeiro artigo], que até certo ponto [Max Fischer] parecia deixar-se influenciar misteriosamente pela "Lista Otto" [Otto Abbetz], a lista de proibições feita pelos nazistas na França; que editava autores decrépitos ou medíocres em quantidade alarmante, trazendo para aqui o rebotalho da cultura francesa; que, mais ainda, havia publicado livros de escritores abertamente colaboracionistas, como André Billy e Pierre Gaxotte, sem falar no general Weygand. [...] Veio então o sr. Max Fischer, diretor da referida editora, e, no seu estilo inimitável, escreveu uma carta ao diretor do Diário Carioca, tentando rebater as críticas de que foi objeto e proclamando-se ardente patriota e anti-nazista.// Ora, o anti-nazismo categórico do sr. Fischer é uma novidade, em letra de forma, no Brasil [...] mas enquanto não sopravam sobre a Alemanha os ventos da derrota, nenhum jornalista foi capaz de lhe arrancar qualquer definição positiva nesse sentido, tantos eram os circunlóquios em que o sr. Fischer envolvia a sua natural dubiedade. Agora, ele surge $[. .$.$] e afirma textualmente: 'deixei a França porque recusei-me a trabalhar sob o controle$ dos alemães'. Só resta diante disso aos anti-fascistas militantes saudar a chegada do novo e tardio companheiro. ${ }^{33}$
}

Moacir reforça a sua "constatação", demonstrando estranheza no fato de Fischer ter se esquecido de publicar em seu "negocinho", Malraux, Maritain, Bernanos, Jean Cassou "e tantos outros", intelectuais comprometidos com ideia de resistência francesa. Ao escrever a Moacir, em 28 de janeiro, Mário parece mostrar-se convencido dos argumentos ventilados no artigo: "Esse caso do Fischer!, nem é bom falar! Sobre ele só quem me prevenira fora o Murilo... que trabalhara pro Fischer! e com argumentos de Murilo. Não dei atenção. Está claro que sei que não é crime nem erro, mas me aborrece ter dois livros com ele, agora que você esclarece mesmo as coisas. Se ele passar mais de um ano sem tirar o Belazarte, tiro o livro da Americ. O que é ótimo, pra sair logo aqui nas "Obras comple-

${ }^{31}$ Carta de Mário de Andrade a Murilo Miranda, 29 out. 1942. Mário de Andrade. Cartas a Murilo Miranda, 1934-1945. op. cit., p. 131.

32 Acusa Mário de Andrade: 'Todos são responsáveis"', Diretrizes, a.4, n 184, Rio de Janeiro, 6 jan. 1944, pp. 1 e 25, em Telê Ancona Lopez. Entrevistas e Depoimentos. São Paulo, T.A. Queiroz, 1983, p. 109

${ }^{33}$ Moacir Werneck de Castro. Resposta a um editor francês. [Diário Carioca, Rio de Janeiro, 24 jan. 1944]. (Arquivo Mário de Andrade, Série Matéria Extraída de Periódicos, IEB-USP). 
tas" que é muito provável o Martins assine contrato comigo. De boca já estamos firmados". ${ }^{34}$

A correspondência entre Mário e Max Fischer, sintomaticamente, silencia-se.

"o corpo da obra literária e a história deste corpo"

Guilherme Figueiredo, com dificuldade de encontrar assunto para sua coluna jornalística no Rio de Janeiro, recorre a Mário de Andrade, em carta de 18 de julho de 1944. O destinatário, que já lhe valera em outra ocasião, deixou anotado na terceira página da missiva: "Dar como assunto os 'gramaticalismos' dos revisores que corrigem os livros da gente. Meu caso "os personagens" que saiu "as personagens". 35

Um dos aspectos centrais do projeto nacionalista de Mário de Andrade foi a sua proposta de atualização da literatura brasileira, no território da expressão linguística. Significava, no caso, refletir criticamente sobre a força da oralidade que marcaria tão fundamente Macunaima e os contos de Belazarte. Explica Mário a seu primo estudioso da língua portuguesa, Pio Lourenço Corrêa, em anotação à margem de página de Amar, verbo intransitivo, a ele ofertado, em 1927, para encetar, no próprio livro, um diálogo sobre questões vernáculas: "Desque principei abrasileirando minha literatura, tomei sempre bem tento nisto: se emprego termos, locuções, sintaxes do povo, não faço fala do povo porém literatura, isto é, busco enobrecer na linguagem escrita os monumentos populares". ${ }^{36}$ Conduzindo com seriedade o seu propósito, Mário travou, muitas vezes, queda de braços com os revisores dos periódicos para os quais colaborou. Prova disso pode ser observada no conjunto de textos que compõe o manuscrito dos Filhos da Candinha (previsto para dois volumes), por ele guardado em seu arquivo. A cada passo, principalmente no jornal O Estado de S. Paulo e no Diário de Notícias, do Rio de Janeiro, a caneta de Mário vai, nos textos, "consertando" a colocação dos pronomes transfigurada pelos revisores. No artigo "Calor" (1939), faz o "Lembrei-me" que inicia um período vigorar em sua forma original "Me lembrei". Em "João Alphonsus" (1944), restitui o "pra" onde os puristas da imprensa desejaram "para". Patenteia-se, nesses recortes, o trabalho miúdo de um escritor consciente de seus meios de expressão.

Em setembro de 1939, Mário, bem-humorado, evidenciava em Surto, Revista Mensal de Cultura, de Belo Horizonte, o quanto a intervenção dos revisores ou o erro de leitura no trabalho de transcrição podia ser nefasta para o procedimento interpretativo:

${ }^{34}$ Carta de Mário de Andrade a Moacir Werneck de Castro, 28 jan. 1944. Moacir Werneck de Castro. Mário de Andrade: exílio no Rio. Rio de Janeiro, Rocco, 1989, p. 213.

${ }^{35}$ Carta de Guilherme Figueiredo a Mário de Andrade, 18 jul. 1944 (Arquivo Mário de Andrade, Série Correspondência, IEB-USP).

${ }^{36}$ Marlene Gomes Mendes. Diálogo Mário e "Tio Pio". Revista do Instituto de Estudos Brasileiros, São Paulo, n. 36, p. 201. 
Erros tipográficos. Blaise Cendrars me comunicou que tendo escrito "artistes", o tipógrafo emendou pra "âmes tristes". Numa poesia de Cocteau, publicada em revista, vinha "Mon âme se céleste". Adorei o verbo "célester", chamando a atenção de Sérgio Milliet, que concordou comigo. Mais tarde, em livro, a poesia saiu consertada pra "Mon âme se déleste". Era uma ninharia. Comigo conheço dois casos bons. Uns "fatores destrutivos" que se reduziram a "quatorze distintivos", e especialmente, ôh que martírio foi! Uma "prosa estilizada" que o tipógrafo castigou em "prosa esterilizada". Desde esse dia nunca mais me preocuparam doutrinas estéticas. ${ }^{37}$

O olhar atento de Mário também flagrou infidelidades textuais na plaquete de sua conferência "O movimento modernista", editada em 1942, no Rio de Janeiro, pela Casa do Estudante do Brasil. Partilhou com Murilo Miranda, em 3 de julho, a sua descoberta: "Li e parece que só tem dois errinhos de impressão: um 'tive a coragem' na pág. 14 em que nunca pus o artigo, e um 'Paulo Prado fator' na pág. 23 que é 'fautor', palavra que o linotipista decerto não conhecia". ${ }^{38}$

Em 20 de dezembro de 1944, às vésperas de receber o estropiado Belazarte, Mário escreve a Rodrigo Mello Franco Andrade, seu amigo e diretor do Serviço do Patrimônio Histórico e Artístico Nacional, a quem devia prestar contas da pesquisa que estava concluindo sobre a obra do "músico, pintor, arquiteto e talvez entalhador", ${ }^{39}$ Padre Jesuíno do Monte Carmelo, nascido em Santos em 1764. Refere-se, na carta, à prevista edição do ensaio: "Há o caso da linguagem. Francamente não estou disposto a abrir mão da minha linguagem, embora a tenha feito a mais discreta que pude... sentir. Aí você entra, tem que entrar com a sua autoridade indiscreta, tenha a paciência. Você corrige como quiser: eu abaixo a cabeça e obedeço, como funcionário. Ponha isso nas costas do Manuel [Bandeira]... Sempre ficados todos nós certos que na inteira reedição do trabalho no conjunto das 'obras completas' ele sairá como eu independentemente o escrever". ${ }^{40}$

Belazarte, agora, transfigurado linguisticamente à revelia de seu autor, batia à porta do sobrado da Rua Lopes Chaves, 546, na Barra Funda paulistana. Imagina-se, agora, a leitura penosa de Mário, que, aflito, empunhando o lápis vermelho e preto (determinando, possivelmente, duas leituras), criva o volume correções. Na página de rosto, em vermelho, anota: "45-46-55-56-95-102-105107-108-178-179-191-197"; e em azul: "Erros novos: 197-". Na realidade, muito mais páginas alojaram toda sorte de gralhas que punham a perder um projeto literário.

${ }^{37}$ Mário de Andrade. Folhas d'Álbum. Surto. Revista Mensal de Cultura, a.4, n.8, Belo Horizonte, set. 1939, p. 3. Reproduzido em Mário de Andrade. Mário, Otávio: Cartas de Mário de Andrade a Otávio Dias Leite (1936-1944). Organização, introdução e notas de Marcos Antonio de Moraes. São Paulo, IEBUSP/Oficina do Livro Rubens Borba de Moraes/Imprensa Oficial; 2006, pp. 112-114.

${ }^{38}$ Carta de Mário de Andrade a Murilo Miranda, 3 jul. 1942. Mário de Andrade. Cartas a Murilo Miranda, 1934-1945. Op. cit., p. 117.

${ }^{39}$ Andrade, Mário de. Padre Jesuíno do Monte Carmelo. São Paulo, Martins, 1963.

${ }^{40}$ Mário de Andrade. Cartas de Trabalho: Correspondência com Rodrigo Mello Franco de Andrade, 1936-1945. Ed. prep. por Lélia Coelho Frota. Brasília, MEC/SPHAN/PróMemória, 1981, p. 185. 
O negligente trabalho editorial desconsiderou, em certas passagens, o "pra" da expressão oralizada de Belazarte, trocando-o por "para", deturpando-a em sua raiz; igualmente, a edição deixou de cumprir o acento que Mário, sistematicamente, colocava sobre o "a" do "pra", ao sinalizar a contração da preposição e do artigo ("chegou-se prà janela", "correndo prá chacra" etc.); 41 "stava", forma oral beneficiada pela epêntese, teve a vogal "e" restituída; a edição ainda desnaturalizou a fala popular do narrador, ao substituir o "rúim", pelo "ruim" da norma culta etc.

No campo lexical, o diagramador minou as narrativas: "barro" virou "bairro"; "beiços" passou a "beijos"; "agradou", a "agarrou"; "pernas", a "penas"; "bandós", a "bandos"; "chamar", a "cramar"; "reflexo", a "reflexão; "vestido de cassa" tornou-se "de casa"; "dona Marina" foi rebatizada de "dona Farina", etc.; as locuções "não-sei-o-quê", "de-tarde", características da produção literária de Mário de Andrade, perderam a força estilística ao se verem mutiladas do hífen;42 em contrapartida, "milréis", "malestar" etc. ganharam, indevidamente, o traço de união.

Sob a chancela da Americ-Edit, a edição incorporou e suprimiu palavras, saltou linha; modificou, aqui e ali, expressões e pontuação. Entre tantos exemplos, no conto "Menina de olho no fundo", lê-se "Maria, vá chamar a mamãe", quando, seguindo a indicação de Mário, à margem da página, deveria encontrar-se "chamar mamãe"; e nessa mesma narrativa, toda uma linha foi esquecida, caso típico de "salto-bordão": ${ }^{43}$ onde o escritor queria ler "um corpo que não era fraco não: capaz de aguentar com a dona que encostasse nele [...]", depara-se apenas com "um corpo que encostasse nele"; faz, então, com a caneta, o ajuste na página.

Em suma, o que se apresentava ao público era um livro sem valor, impróprio para o conhecimento do ideário estético de Mário de Andrade, tanto quanto uma obra incapaz de favorecer o desvelamento da significação mais profunda do

${ }^{41}$ Mário de Andrade, em carta 21 de julho de 1925, já advertia o jovem poeta Pedro Nava: "Do abrasileiramento de linguagem de você tenho duas observações: Você está acentuando todos os pras. Isso traz confusão Nava. Acentue só quando tiver contração com artigo. Vou prá escola. Me dê pra mim. Não acha essa diferenciação razoável?" (Mário de Andrade. Correspondente contumaz: Cartas de Mário de Andrade a Pedro Nava, 1925-1944. Ed. prep. por Fernando da Rocha Peres. Rio de Janeiro: Nova Fronteira, 1982, p. 53).

${ }^{42}$ Em carta a Manuel Bandeira, em $1^{\circ}$ de fevereiro de 1933, Mário alude à sua "escrita... falada" e se refere à seu vezo de criar expressões utilizando o hífen: "de certo pelo contato do alemão, tomei muito costume, você deve ter observado, de unir as locuções, por meio de hífen sala-de-jantar, não-sei-o-quelá, etc." Andrade, Mário de; Bandeira, Manuel. Correspondência. op. cit, p. 552.

${ }^{43}$ Em Introdução à crítica textual, César Nardelli Cambraia define o "salto-bordão": "quando há no modelo utilizado para a cópia duas palavras iguais em pontos diferentes de uma mesma página de um manuscrito ou impresso, não raramente costuma-se saltar o texto que há entre essas duas palavras. Isto dá-se porque o copista não percebe que, ao retornar os olhos para o modelo, após ter registrado na sua cópia a primeira ocorrência da palavra em questão, seus olhos se fixam em uma palavra igual, mas em um ponto situado adiante no modelo". (São Paulo, Martins Fontes, 2005, p. 10). Uma eficiente síntese da "tipologia de erros" - "adição, omissão, alteração da ordem e substituição" -, pode ser consultada no mencionado manual, pp. 78-85. 
narrador Belazarte. Esse mesmo livro com emendas, alçando-se à categoria de "exemplar de trabalho", 44 ao ser conservado por Mário em seu arquivo, serviu, em 2008, para o estabelecimento de texto apurado dos contos, trabalho de Aline Nogueira Marques, sob a orientação da Profa. Dra. Telê Ancona Lopez. ${ }^{45}$ O vasto conjunto de lapsos retomados e corrigidos por Mário, no próprio volume, possibilita, hoje, uma compreensão mais plena da natureza das idiossincrasias de seu projeto linguistico. Favorece, igualmente, a correta observação do que seja "erro" (alteração não-autoral) e "originalidade" (transgressão estratégica da norma linguística; o experimentalismo narrativo, etc.) na obra do autor de Macunaíma, tão marcada pelo experimentalismo. ${ }^{46}$

Conhecendo as peripécias editoriais de Belazarte, por fim, nos aproximamos um pouco do "corpo da obra literária" e da "história deste corpo", "aspectos acessórios, mas indispensáveis" 47 do trabalho hermenêutico, como nos ensina Antonio Candido em seu prestadio Noções de análise histórico-literária.

${ }^{44} \mathrm{O}$ estudo dos manuscritos de Mário de Andrade, aparelhado pelos fundamentos teóricos da crítica literária, textual e genética, vincula-se ao Projeto Temático Estudo do processo de criação de Mário de Andrade nos manuscritos de seu arquivo, em sua correspondência, em sua marginália e em suas leituras (IEB-USP/FAPESP), coordenado pela Prof ${ }^{a}$. Dra ${ }^{\mathrm{a}}$. Telê Ancona Lopez.

${ }^{45}$ Aline Nogueira V. Marques. Uma história que Belazarte não contou. Mário de Andrade. Os contos de Belazarte. Rio de Janeiro, Agir, 2008, pp. 9-24.

${ }^{46} \mathrm{Na}$ comunicação "A importância da correspondência ativa, passiva e complementar do Acervo Guimarães Rosa (IEB/USP), no I Encontro de Crítica Textual: O manuscrito moderno e as edições (São Paulo, FFLCH-USP, 1986) as pesquisadoras Edna Maria Fernandes dos Santos Nascimento, Iná Valéria Rodrigues e Lenira Marques Covizzi se detêm em questão similar, aludindo à expressão literária do criador de Grande sertão: veredas, a qual "naturalmente degradada pelas suas reproduções, corre o risco de ser herdada inadequadamente pelo futuro. Na medida em que toda a diferença - dominante estética do período - poderá ser aceita enquanto criação. Poder-se-á, aí, confundir erro com originalidade. Tanto ao nível do leitor comum quanto no dos analistas; que terão os seus trabalhos invalidados ao manipular textos incorretos". (p. 89).

${ }^{47}$ Antonio Candido. Noções de análise histórico-literária. São Paulo, Associação Editorial Humanitas; 2005. pp.13-4. 